\title{
Morbid Placental Adhesion -A Nightmare for Obstetricians
}

Abnormal placentation (accreta, increta and percreta) has emerged over uterine atony as the leading indication for peripartum hysterectomy due to obstetric haemorrhage ${ }^{1}$. Once a rare occurrence, morbidly adherent placenta (Placenta accreta syndrome) is now becoming an increasingly common complication of pregnancy, mainly due to the increasing rate of Caesarean delivery about 10 times more over the past 50 years ${ }^{2}$.

Placenta accreta syndrome is the abnormal adherence of the chorion of the placenta to the myometrium of the uterus. Normally there is tissue intervening between the chorionic villi and the myometrium, but in 'placenta accreta, the vascular processes of the chorion grow directly in the myometrium. Placenta accreta can progress into placenta percreta.

An incidence of 1 : 533 births for the period from 1982 to 2002 , much greater than previous reports ranging from $1: 4027$ to $1: 2510$ births in the 1970 s to1980s, suggesting that this increase is mainly the result of the increasing rate of cesarean delivery ${ }^{3}$.

Women at greatest risk of placenta accreta are those who have myometrial damage caused by a previous cesarean delivery with either anterior or posterior placenta previa overlying the uterine scar. The authors of one study found that in the presence of a placenta previa, the risk of placenta accreta was 3\%, 11\%, 40\%, $61 \%$, and $67 \%$ for the first, second, third, fourth, and fifth or greater repeat cesarean deliveries, respectively ${ }^{4}$. Placenta previa without previous uterine surgery is associated with a $1-5 \%$ risk of placenta accreta.

Other reported risk factors include any condition resulting in myometrial tissue damage followed by a secondary collagen repair, such as previous myomectomy, endometrial defects due to vigorous curettage resulting in Asherman syndrome ${ }^{5}$, submucous leiomyomas, thermal ablation, advanced maternal age, multiparity, hypertensive disorders of pregnancy, smoking, congenital or acquired uterine defects (such as uterine septa), ectopic implantation of placenta (including cornual pregnancy.

The exact pathogenesis of placenta accreta is unknown. But decidual maldevelopment or the absence of decidua is of greater importance in the pathogenesis ${ }^{6}$. The abnormal expression of growth, angiogenesis, and invasion-related factors in the trophoblast populations (the cytotrophoblast secretes factors that favor invasion)are the main factors responsible for the occurrence of placenta accreta ${ }^{7}$.

The presence and increasing number of lacunae within the placenta at 15-20 weeks of gestation have been shown to be the most predictive ultrasonographic signs of placenta accreta in $2^{\text {nd }}$ trimester, with a sensitivity of $79 \%$ and a positive predictive value of $92 \%{ }^{8} \&$ should undergo follow-up imaging in the third trimester(32-34 weeks) with attention to the potential presence of placenta accreta.

Sonographic findings that may be suggestive of placenta accreta include:

1. Loss of normal hypoechoic retroplacental zone

2. Multiple vascular lacunae (irregular vascular spaces) within placenta, giving "Swiss cheese" or moth-eaten" appearance

3. Blood vessels or placental tissue bridging uterineplacental margin, myometrial-bladder interface, or crossing the uterine serosa

4. Retroplacental myometrial thickness of $<1 \mathrm{~mm}$

5. protrusion of the placenta into the bladder

6. Numerous coherent vessels visualized with 3dimensional power Doppler in basal view and

7. Turbulent flow through the lacunae on Doppler ultrasonography ${ }^{8}$.

The use of power Doppler, color Doppler, or threedimensional imaging does not significantly improve the diagnostic sensitivity compared with that achieved by grayscale USG along? . 
MRI is considered an adjunctive modality \& is able to outline the anatomy of the invasion and relate it to the regional anastomotic vascular system, enabled confirmation of parametrial invasion and possible ureteral involvement with a very good sensitivity and specificity for this disorder but MRI is more costly than USG and requires both experience and expertise in the evaluation of abnormal placental invasion ${ }^{10}$.

Women with placenta accreta are usually delivered by a cesarean section \& except in specific cases, hysterectomy remains the treatment of choice for patients with placenta accreta.

It is better to perform the surgery under elective, controlled conditions rather than as an emergency without adequate preparation. Improved outcomes have been demonstrated when these patients give birth in specialized tertiary centers with all emergency facilities ${ }^{11}$.

In addition, regardless of the management option made, prevention of complications ideally requires a multidisciplinary team approach .The multidisciplinary team should include a gynecologic surgeon experienced in pelvic surgery, maternal-fetal medicine specialist, a blood bank team prepared to administer multiple blood components, experienced anesthesiology personnel who are skilled in obstetric anesthesia, skilled urologists in case a bladder resection or repair might be required, experienced intensivists for postpartum care, and an experienced neonatologist.In cases where pelvic artery catheterizations are used, an experienced interventional radiologist is also required ${ }^{12}$.

The timing of delivery in cases of suspected placenta accreta must be individualized depending on patient circumstances and preferences. This decision should be made jointly with the patient, obstetrician, and neonatologist. Patient counseling should include discussion of the potential need for hysterectomy, the risks of profuse hemorrhage, and possible maternal mortality \& morbidity. The results of a recent decision analysis suggested that combined maternal and neonatal outcomes are optimized in stable patients with delivery at 34-35 weeks of gestation without amniocentesis in a view to avoid an emergency cesarean on the one hand and to minimize complications of prematurity on the other $^{11}$.
The American Society of Anesthesiologists task force on obstetric anesthesia suggested that general anesthesia may be the most appropriate choice in some circumstances, including cases where severe hemorrhage is anticipated ${ }^{13}$. The decision to administer antenatal corticosteroids and the timing of administration should be individualized. Generally, the recommended management of suspected placenta accreta is planned preterm cesarean hysterectomy, the standard approach is to leave the placenta in situ, quickly use a "whip stitch" to close the hysterotomy incision, and proceed with hysterectomy.

Data suggest that preoperative ureteric stent placement may help reduce the risk of ureteric injury. If bladder involvement is suspected, cystotomy may be needed to clarify the extent of invasion after devascularization of the uterus is achieved and to ensure ureteric patency if stents were initially not inserted ${ }^{14}$.

Conservative management, which includes delivery by a cesarean section without hysterectomy that includes ligating the cord close to the fetal surface, removing the cord, and leaving the placenta in situ, potentially with partial placental resection to minimize its size. However, this approach should be considered only when the patient has a strong desire for future fertility as well as hemodynamic stability, normal coagulation status, and is willing to accept the risks involved in this conservative approach ${ }^{15}$.

Postoperative complications reported with a conservative approach include severe $\mathrm{PPH}$, postoperative DIC and infection resistant to antimicrobial therapy that may require laparotomy and hysterectomy. Conservative treatment required women adherence to treatment over along postpartum period, which suggests that women may continue to be at risk for severe morbidity and possibly mortality for weeks or even months after delivery ${ }^{16}$.

En Block excision of placenta accreta was first described by palacios et al, in 2004 in a series of 68 cases ${ }^{17}$. This technique permitted resection of invaded myometrium when $50 \%$ or less of the anterior uterine circumference is invaded. After excision the resulting defect was repaired with myometrial pulley suture, similar to horizontal mattress suture. Even with these technique $26 \%$ needs hysterectomy ${ }^{18}$. Except in specific cases, hysterectomy remains the treatment of choice for patients with placenta accreta. 
Current evidence is insufficient to make a firm recommendation on the use of balloon catheter occlusion or embolization internal iliac artery to reduce blood loss and improve surgical outcome ${ }^{19}$.

Placenta accreta is becoming an increasingly scommon complication of pregnancy because of increasing incidence of caesarean section. So every attention should be paid to minimize the rate of primary caesarean section \& to encourage the VBAC( vaginal birth after previous C. section).

As Prenatal diagnosis seems to be a key factor in optimizing the counseling, treatment, and outcome of women with placenta accreta. In addition, regardless of the management option made, prevention of complications ideally requires a multidisciplinary team approach. Cesarean hysterectomy is probably the preferable treatment. Conservative management should only be used in highly selected cases. Even though there may be a rationale to add adjuvant therapy in such cases, there is no evidence-based proof that such therapy is actually of benefit or that it is not in fact harmful.

\section{(J Bangladesh Coll Phys Surg 2019; 37: 1-3)}

DOI: http://dx.doi.org/10.3329/jbcps.v37i1.39280

\section{Prof. Kohinoor Begum}

Prof. Obs \& Gynae, Popular Medical College, Dhaka, Counselor, Bangladesh College of Physicians and Surgeons

\section{References:}

1. Bajwa SK, Singh ABS. Contemporary issues in the management of abnormal placentation during pregnancy in developing nations: an Indian perspective. Int J Crit Illn Inj Sci. 2013;3(3):183189. doi: $10.4103 / 2229-5151.119197$.

2. Dandolu V, Graul AB, Lyons AMD. Obstetrical Hysterectomy, cesarean delivery and abnormal placentation. J Matern Fetal Med. 2012;25(1):74-77. doi: 10.3109/14767058.2011.565391.

3. S. Wu, M. Kocherginsky, and J. U. Hibbard, "Abnormal placentation: twenty-year analysis," American Journal of Obstetrics and Gynecology.2005;192(5) 1458-1461.

4. Silver RM, Landon MB, Rouse DJ, Leveno KJ, Spong CY, Thom EA, et al. Maternal morbidity associated with multiple repeat cesarean deliveries. National Institute of Child Health and Human Development Maternal-Fetal Medicine Units Network. Obstet Gynecol 2006;107:1226-32.

5. Al-Serehi A, Mhoyan A, Brown M, Benirschke K, Hull A, Pretorius DH. Placenta accreta: an association with fibroids and
Asherman syndrome. J Ultrasound Med 2008;27:1623-8.

6. K. Benirschke, P. Kaufmann, and R. N. Baergen, Pathologyof the Human Placenta, Springer, New York, NY, USA, $5^{\text {th }}$ edition, 2006.

7. J.-J. Tseng and M.-M. Chou, "Differential expression of growth, angiogenesis and invasion-related factors in the development of placenta accreta," Taiwanese Journal of Obstetricsand Gynecology. 2006; 45(2) 100-106.

8. Comstock CH, Love JJ Jr, Bronsteen RA, Lee W, Vettraino IM, Huang RR, et al. Sonographic detection of placenta accreta in the second and third trimesters of pregnancy. Am J Obstet Gynecol 2004;190:1135-40.

9. Warshak CR, Eskander R, Hull AD, Scioscia AL, Mattrey RF, Benirschke K, et al. Accuracy of ultrasonography and magnetic resonance imaging in the diagnosis of placenta accreta. Obstet Gynecol 2006;108:573-81.

10. D'Antonio F, Iacovella C, Palacios-Jaraquemada J, Bruno CH, Manzoli L, Bhide A (July 2014). "Prenatal identification of invasive placentation using magnetic resonance imaging: systematic review and meta-analysis". Ultrasound in Obstetrics \& Gynecology : the Official Journal of the International Society of Ultrasound in Obstetrics and Gynecology. 44 (1): 8-16. doi:10.1002/uog.13327. PMID 24515654.

11. B. K. Robinson and W. A. Grobman, "Effectiveness of timing strategies for delivery of individuals with placenta previa and accreta," Obstetrics and Gynecology.2010;116(4)835-842.

12. A. G. Eller, M. A. Bennett, M. Sharshiner et al., "Maternal morbidity in cases of placenta accreta managed by a multidisciplinary care team compared with standard obstetric care,"Obstetrics and Gynecology. 2011;117(2):331-337.

13. J. L. Hawkins, J. F. Arens, B. A. Bucklin et al., "Practice guidelines for obstetric anesthesia: an updated report by the American Society of anesthesiologists Task Force on obstetric anesthesia," Anesthesiology. 2007;106(4)843-863.

14. A. G. Eller, T. T. Porter, P. Soisson, and R. M. Silver, "Optimal management strategies for placenta accreta," An International Journal of Obstetrics and Gynaecology.2009;116(5): 648-654.

15. G. Kayem, C. Davy, F. Goffinet, C. Thomas, D. Cl'eent, and D. Cabrol, "Conservative versus extirpative management in cases of placenta accreta," Obstetrics and Gynecology. 2004;104(3): 531-536.

16. A. Weinstein, P. Chandra, H. Schiavello, and A. Fleischer, "Conservative management of placenta previa percreta in a Jehovah's Witness. Obstetrics and Gynecology.2005;105 (5):1247-1250.

17. Bretelle F, Courbiere B, Mazouni C, Agostini A, Cravello L, Boubli L, et al. Management of placenta accreta: morbidity and outcome. Eur J Obstet Gynecol Reprod Diol 2007;133:34-9.

18. Chandrafaran E, Rao S, Belli AM, Arukumaran S. The Triple P procedure as a conservative surgical alternative to peripartum hysterectomy for placenta percreta. Int J Gynae Obstet 2012; 117:191-4.

19. Bishop S, Butler K, Monaghan S, Chan K, Murphy G, Edozien L. Multiple complications following the use of prophylactic internal iliac artery balloon catheterisation in a patient with placenta percreta. Int J Obstet Anesth 2011; 20:70-3. 